\title{
Dry Sliding Wear Behavior of 38CrNi3MoV Steel at Elevated Temperatures
}

\author{
Yong Lian ${ }^{1,2, *}$, Wen Gao ${ }^{1,3}$, Chao Zhao ${ }^{1,2}$, Minyu Ma ${ }^{1,2}$, Jinfeng Huang ${ }^{4}$ and Jin Zhang ${ }^{1,2, *}$ \\ ${ }^{1}$ Institute for Advanced Materials and Technology, University of Science and Technology Beijing, Beijing 100083, China \\ ${ }^{2}$ Beijing Key Laboratory for Corrosion, Erosion and Surface Technology, Beijing 100083, China \\ ${ }^{3}$ Institute of Applied Technology, Chinalco Materials Application Research Institute Co., Ltd., Beijing 100083, China \\ ${ }^{4}$ State Key Laboratory for Advanced Metals and Materials, University of Science and Technology Beijing, Beijing 100083, China
}

Friction and wear behavior of $38 \mathrm{CrNi} 3 \mathrm{MoV}$ steel were investigated from $25-600^{\circ} \mathrm{C}$ using a pin-on-disc elevated temperature tester. Thereafter, the hot hardness of the pin and disc, tribo-oxides phase composition, worn surface and interface morphology were examined to understand the wear mechanisms. The results show that the $38 \mathrm{CrNi} 3 \mathrm{MoV}$ steel presented different wear rates at various temperatures. The ambient temperature is the main factor affecting the formation of tribo-oxides. While, the final morphology of tribo-oxides remaining on the worn surface depended on the difference between the disc's hot hardness and the pin's hot hardness $\left(H_{\text {disc }}-H_{\text {pin }}\right)$. Adhesive and abrasive wear, mild oxidative wear, severe oxidative wear, and mild oxidative wear prevailed at $25,200,400$, and $600^{\circ} \mathrm{C}$, respectively.

[doi:10.2320/matertrans.MT-M2020032]

(Received January 22, 2020; Accepted September 7, 2020; Published October 16, 2020)

Keywords: dry sliding, elevated temperature, hot hardness, tribo-oxides, wear mechanisms

\section{Introduction}

Wear at elevated temperature has become an important problem in the fields of energy, transport, materials processing, engines, and armaments. ${ }^{1-3)}$ In order to improve wear resistance at elevated temperature and prolong the service life of the materials, many studies have been carried out and conclude that the loss of mechanical strength and enhanced oxidation of materials surface are the two most important factors that affect the wear process. ${ }^{4-6)}$

The oxidation of materials during the wear process has been systematically studied by many researchers. Fink ${ }^{7)}$ first identified the effect of oxidation on wear in 1930. Archard and $\mathrm{Hirst}^{8)}$ reported the relationship between tribo-oxides and wear and classified wear into the mild wear and severe wear categories. Wilson and Quinn ${ }^{9-11)}$ separately established the theory of oxidative wear of steel based on different experimental conditions in the 1980s. Their model suggested that tribo-oxides can hinder metal-metal contact to reduce wear and oxidation wear depends only on the tribo-oxides.

Researchers found that the matrix also played an important role in the wear test, especially under severe conditions, such as higher temperatures or heavier loads. ${ }^{12-16)}$ Wang $^{17-19)}$ studied the transition of mild to severe wear in the oxidative and transition regions and analyzed the mechanisms surrounding how the matrix and tribo-oxides jointly affect the wear process. The influence of the variation of matrix property on wear behavior was considered and it was determined that tribo-oxides reduced wear if the matrix retained the necessary strength to support tribo-oxide layer. ${ }^{16)}$

The effect of the hardness of the material on the wear behavior was also studied, and it was found that the hardness ratio of the disc to the pin $\left(H_{\text {disc }} / H_{\text {pin }}\right)$ was the key factor affecting the material wear characteristics. ${ }^{20}$ However, studies on the role of material matrix properties have been limited to the mechanical properties of materials at room

*Corresponding authors, E-mail: zhangjin@ustb.edu.cn, liany09@126.com temperature. There is still little research on the relationship between material properties and wear behavior at elevated temperatures, which must be further investigated.

In this work, we examined the influence of the change of the properties of the sliding material and the counterface materials (the pin and disc) under elevated temperatures on the wear properties of gun-barrel used steel $38 \mathrm{CrNi} 3 \mathrm{MoV}$. The friction and wear behavior of $38 \mathrm{CrNi} 3 \mathrm{MoV}$ steel under various ambient temperatures was investigated using the pinon-disc type wear tester. The hot hardness of the disc and pin at various ambient temperatures and the worn surface and interface of the sample were presented. The influence of the hot hardness of the disc and pin under various ambient temperatures on the tribo-oxides and the wear behavior of the pin was also analyzed.

\section{Experimental Procedure}

$38 \mathrm{CrNi} 3 \mathrm{MoV}$ and AISI M2 steels were used as the pin and disc specimens, respectively. The chemical compositions of these two materials are shown in Table 1 . The $38 \mathrm{CrNi} 3 \mathrm{MoV}$ steel was supplied as a hot-forge bar with a diameter of $70 \mathrm{~mm}$. Samples from this bar were heated to $870^{\circ} \mathrm{C}$ and cooled in air, austenitized at $870^{\circ} \mathrm{C}$ for $1 \mathrm{~h}$ followed water quenching and then tempered at $610^{\circ} \mathrm{C}$ for 2 hours to attain tempered sorbite (39-41 HRC). M2 steel was taken from a hot rolled bar of $80 \mathrm{~mm}$ in diameter. Samples of M2 steel were austenitized at $1180^{\circ} \mathrm{C}$ for $1 \mathrm{~h}$, then water quenched and tempered three times at $540^{\circ} \mathrm{C}$ for 2 hours to attain tempered martensite with carbides (62-64 HRC).

The measurements of hot hardness were carried out up to $600^{\circ} \mathrm{C}$ using an AKASHI AVK-A type hot hardness tester with a Vickers indenter at a load of $500 \mathrm{~g}$ and a dwell time of $5 \mathrm{~s}$. The specimens were heated to the test temperature and hold for $10 \mathrm{~min}$ in argon atmosphere. Each hardness value presented is the average of 5 measurements.

Wear tests were carried out on a pin-on-disc MG-2000 wear test apparatus equipped with a heater to obtain ambient temperatures up to $800^{\circ} \mathrm{C}$. $38 \mathrm{CrNi} 3 \mathrm{MoV}$ steel was selected 
Table 1 Chemical composition of material for experiment (mass\%).

\begin{tabular}{cccccccccccc}
\hline Materials & $\mathrm{C}$ & $\mathrm{Si}$ & $\mathrm{Mn}$ & $\mathrm{Cr}$ & $\mathrm{Ni}$ & $\mathrm{Mo}$ & $\mathrm{V}$ & $\mathrm{W}$ & $\mathrm{Fe}$ \\
\hline 38CrNi3MoV & $0.34-0.41$ & $0.17-0.37$ & $0.25-0.50$ & $1.20-1.50$ & $3.00-3.50$ & $0.35-0.45$ & $0.10-0.25$ & $/$ & Bal. \\
AISI M2 & $0.80-0.90$ & $0.20-0.45$ & $0.15-0.40$ & $3.80-4.40$ & $/$ & $4.4-5.5$ & $1.75-2.20$ & $5.50-6.75$ & Bal. \\
\hline
\end{tabular}

as the pin with dimensions of $6 \mathrm{~mm}$ in diameter and $12 \mathrm{~mm}$ in length and M2 steel was chosen as the discs with dimensions of $70 \mathrm{~mm}$ in diameter and $10 \mathrm{~mm}$ in thickness. The contact surfaces of the pins and discs were ground to reach a roughness $(\mathrm{Ra})$ of about $0.2 \mu \mathrm{m}$ and cleaned with acetone before each test. Experiments were carried out at 25, 200, 400 , and $600^{\circ} \mathrm{C}$ with a load of $200 \mathrm{~N}$. The rotation speed was set as $400 \mathrm{r} / \mathrm{min}$ (sliding velocity of $1.26 \mathrm{~m} / \mathrm{s}$ ), and the total number of tests for each group was 4000 cycles (sliding distance of $753.6 \mathrm{~m}$ ). The wear mass loss of the pin specimen was determined using a FA1004N type electronic balance with an accuracy of $0.1 \mathrm{mg}$. The wear rate was calculated through the volume loss divided by sliding distance, where the volume loss was defined as the mass loss of unit density of $7.83 \mathrm{~g} / \mathrm{cm}^{3}$. At least three tests were performed for each experimental point.

Morphology and composition of the worn surface, subsurface were examined by an FEI Quanta 250 scanning electron microscope (SEM). The morphology of the wear tracks was characterized using a KEYENCE VHX-2000 digital microscope with a depth-of-field imaging system. Phases on the worn surface were identified by a Smart Lab type X-ray diffractometer (XRD) with $\mathrm{Cu} \mathrm{K}_{\alpha}$ radiation, the wavelength of $1.5406 \AA$, the working voltage of $40 \mathrm{kV}$, the working current of $150 \mathrm{~mA}$, the diffraction angle of $20-80^{\circ}$, and the scanning speed of $20^{\circ} / \mathrm{min}$.

\section{Results}

\subsection{Wear performance}

The friction coefficients as a function of time for $38 \mathrm{CrNi} 3 \mathrm{MoV}$ steel pin sliding at various ambient temperatures are shown in Fig. 1. The friction coefficients at various ambient temperatures presented the same trend of variationthey increased rapidly from zero to a certain value at around $30 \mathrm{~s}$ in the initial stage and then oscillated to a certain range (between 0.3-0.4) during the rest wear process.

The key factor that affects the friction coefficient is the contact between the sliding material and the counterface, which includes the deformation of asperities, the migration of wear particles, the plowing of hard asperities, and the formation of tribo-oxides. ${ }^{21,22)}$ In the initial stage of the process, which we termed the run-in or break-in period, ${ }^{23)}$ the friction coefficient increased continuously due to the increased adhesion between the contact surfaces. After the run-in period, a dynamic equilibrium for the formation and migration of the tribo-oxides on the worn surface was reached, causing the wear process to enter a steady-state sliding period.

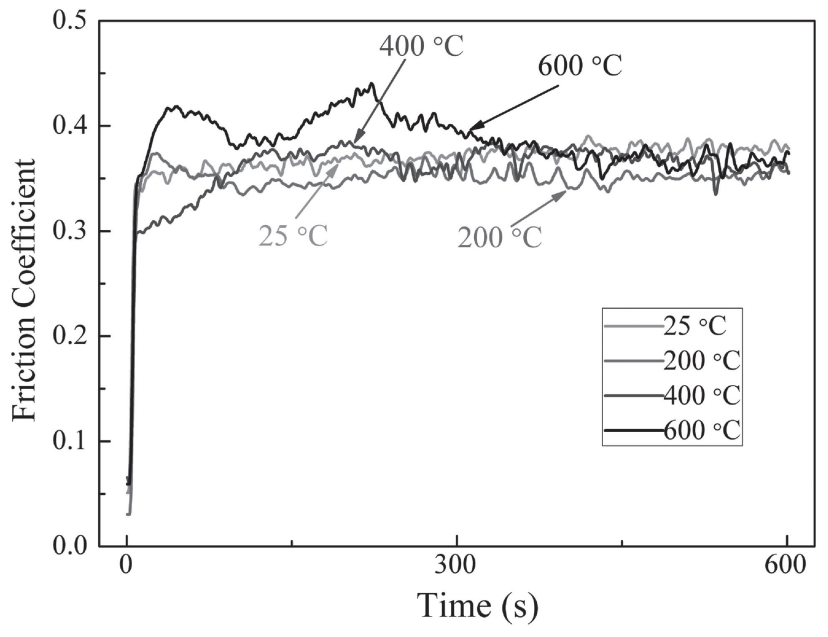

Fig. 1 The variation of friction coefficients in the wear process at various ambient temperatures.

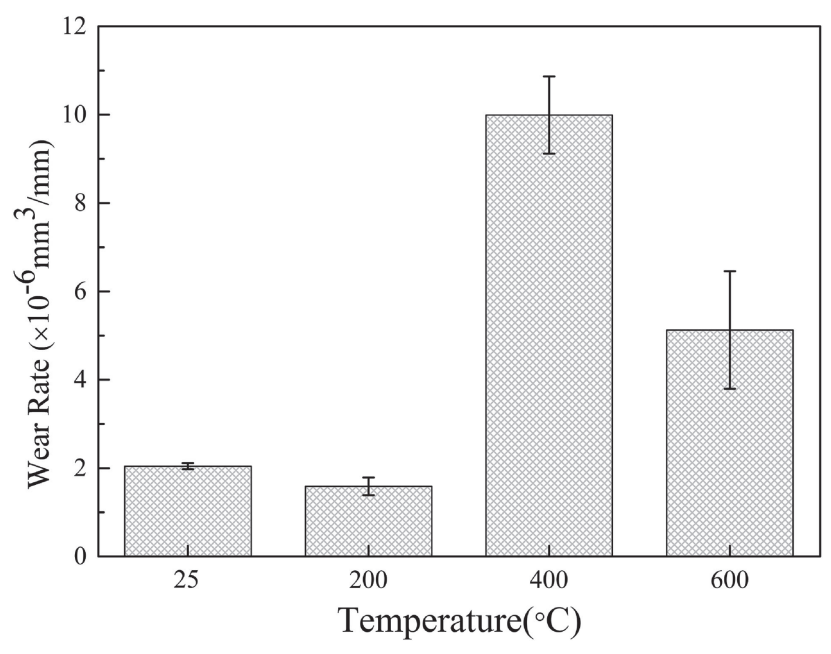

Fig. 2 Wear rates of $38 \mathrm{CrNi} 3 \mathrm{MoV}$ steel at various temperatures.

Figure 2 illustrates the wear rates of $38 \mathrm{CrNi} 3 \mathrm{MoV}$ steel at various temperatures. $38 \mathrm{CrNi} 3 \mathrm{MoV}$ presented a marked variation of the wear rate with increased temperature. The wear rate of $38 \mathrm{CrNi} 3 \mathrm{MoV}$ steel first decreased at $200^{\circ} \mathrm{C}$, then increased at $400^{\circ} \mathrm{C}$, and decreased again at $600^{\circ} \mathrm{C}$.

The wear rate results of both $38 \mathrm{CrNi} 3 \mathrm{MoV}$ pins tested at 25 to $400^{\circ} \mathrm{C}$ are consistent with the results of $\mathrm{H} 13$ and $\mathrm{H} 21$ steel in Ref. 24), 25) for $\mathrm{H} 13$ and $\mathrm{H} 21$ steel. The variation in the wear rate of steels is related to the loss of mechanical strength and enhanced oxidation. ${ }^{4,26)}$ The wear rate of $38 \mathrm{CrNi} 3 \mathrm{MoV}$ decreased at $200^{\circ} \mathrm{C}$ due to the formation of tribo-oxides on the worn surface, hindering the metal-metal 

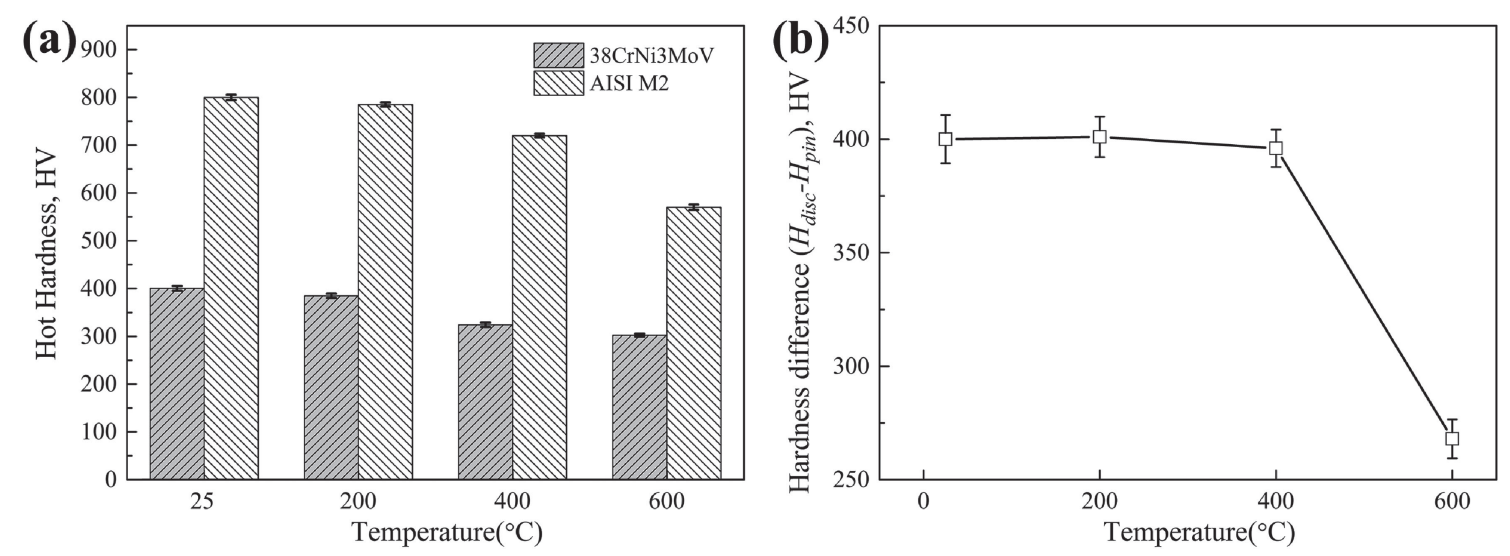

Fig. 3 The hot hardness of M2 steel disc and 38CrNi3MoV steel pin at various temperatures: (a) hot hardness; (b) the difference between the hot hardness of the disc and pin.

contact. When the ambient temperature rose to $400^{\circ} \mathrm{C}$, the matrix softened and did not retain the necessary strength to support the tribo-oxide layer, leading to an increase in the wear rate. According to the former research, ${ }^{24,25)}$ it may be speculated that the wear rate would increase further when the test ambient temperature rose to $600^{\circ} \mathrm{C}$ as the matrix would soften further for the increase in temperature. However, the wear rate of $38 \mathrm{CrNi} 3 \mathrm{MoV}$ decreased instead at $600^{\circ} \mathrm{C}$ in this study. This phenomenon needed to be further analyzed by considering both the matrix properties and the tribo-oxides.

\subsection{Hot hardness of the disc and pin}

The wear of the pin is related to the hardness of not only the pin but also the disc. $\left.{ }^{27}\right)$ Figure 3 shows both the hot hardness of the disc (M2 steel) and pin (38CrNi3MoV steel) and the difference between the hot hardness of the disc and pin $\left(H_{\text {disc }}-H_{\text {pin }}\right)$ at various temperatures. The hot hardness of M2 steel was higher than $38 \mathrm{CrNi} 3 \mathrm{MoV}$ steel at each temperature and the hot hardness of both the disc and pin decreased with the increase of the ambient temperature.

Studies have shown that $\left(H_{\text {disc }} / H_{\text {pin }}\right)$ was the key factor that affected the material wear characteristics. ${ }^{20,28)}$ However, the $\left(H_{\text {disc }} / H_{\text {pin }}\right)$ value was always above 1 at any temperature for the presented $\mathrm{M} 2-38 \mathrm{CrNi} 3 \mathrm{MoV}$ steel tribo-system. Therefore, it was no longer suitable to explain the wear behavior of $38 \mathrm{CrNi} 3 \mathrm{MoV}$ steel using the $\left(H_{\text {disc }} / H_{\text {pin }}\right)$ value. We noted that the hot hardness of the disc dropped sharply and the $\left(H_{\text {disc }}-H_{\text {pin }}\right)$ value for $\mathrm{M} 2-38 \mathrm{CrNi} 3 \mathrm{MoV}$ dropped below $300 \mathrm{HV}$ at $600^{\circ} \mathrm{C}$, which was in accordance with the decrease of the wear rate at this temperature.

\subsection{Analysis of worn surfaces and cross section}

Figure 4 shows the XRD patterns of the worn surface of $38 \mathrm{CrNi} 3 \mathrm{MoV}$ steel at various temperatures. The diffraction peaks for the specimens after wear test at 25 and $200^{\circ} \mathrm{C}$ mainly belonged to $\alpha$-Fe and cubic wüstite $(\mathrm{FeO})$, which indicates that a certain amount of $\mathrm{FeO}$ appeared on the worn surface. Wüstite $(\mathrm{FeO})$ has a hardness of $\sim 317 \mathrm{HV}$ and has good lubricity, ${ }^{29)}$ which decreases the wear and the friction coefficient. When the temperature reached $400^{\circ} \mathrm{C}$, the intensity of the diffraction peak of cubic magnetite $\left(\mathrm{Fe}_{3} \mathrm{O}_{4}\right)$ was higher than $\mathrm{FeO}$, which indicated that a large amount of $\mathrm{Fe}_{3} \mathrm{O}_{4}$ oxide formed on the worn surface. Magnetite has an

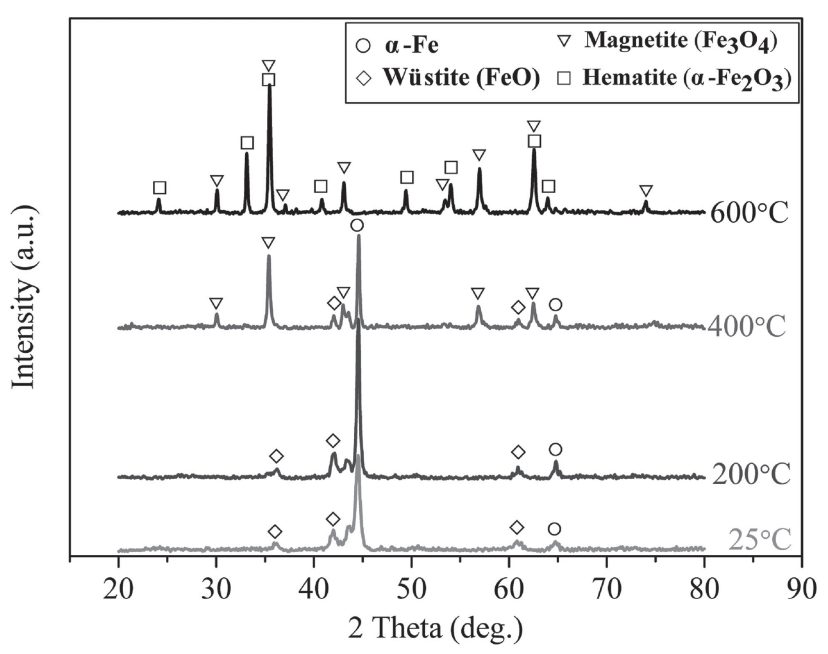

Fig. 4 The XRD patterns of worn surfaces of $38 \mathrm{CrNi3MoV}$ steel after wear test at various temperatures.

intermediate hardness of $\sim 450 \mathrm{HV}$ and can also acts as a lubricant. ${ }^{30)}$ As the ambient temperature reached $600^{\circ} \mathrm{C}$, the peaks corresponding to $\mathrm{Fe}$ disappeared, leaving only the diffraction peak of magnetite $\left(\mathrm{Fe}_{3} \mathrm{O}_{4}\right)$ and hematite $\left(\alpha-\mathrm{Fe}_{2} \mathrm{O}_{3}\right)$. It can be inferred that a large amount of tribo-oxides with a large thickness were formed at this temperature, which caused the X-ray diffraction analysis to be unable to detect the Fe matrix.

The macromorphologies of the worn surfaces of $38 \mathrm{CrNi} 3 \mathrm{MoV}$ steel are shown in Fig. 5. It may be noticed that the worn surfaces at various ambient temperatures represented different oxidative colors in addition to the same furrows along the sliding direction. At $25^{\circ} \mathrm{C}$, the worn surface was light gray overall with a small number of black marks along the sliding direction. The worn surface was yellow, blue and black at 200,400 and $600^{\circ} \mathrm{C}$, respectively. The color of the worn surface reflected the degree of tribooxidation, which was consistent with the XRD results shown in Fig. 4.

Figure 6 shows the morphologies of the worn surface of $38 \mathrm{CrNi} 3 \mathrm{MoV}$ steel at various temperatures observed by a full-focus imaging digital microscope. At $25^{\circ} \mathrm{C}$, a small amount of black oxide could be observed on the worn surface. At $200^{\circ} \mathrm{C}$, the tribo-oxides essentially covered the 


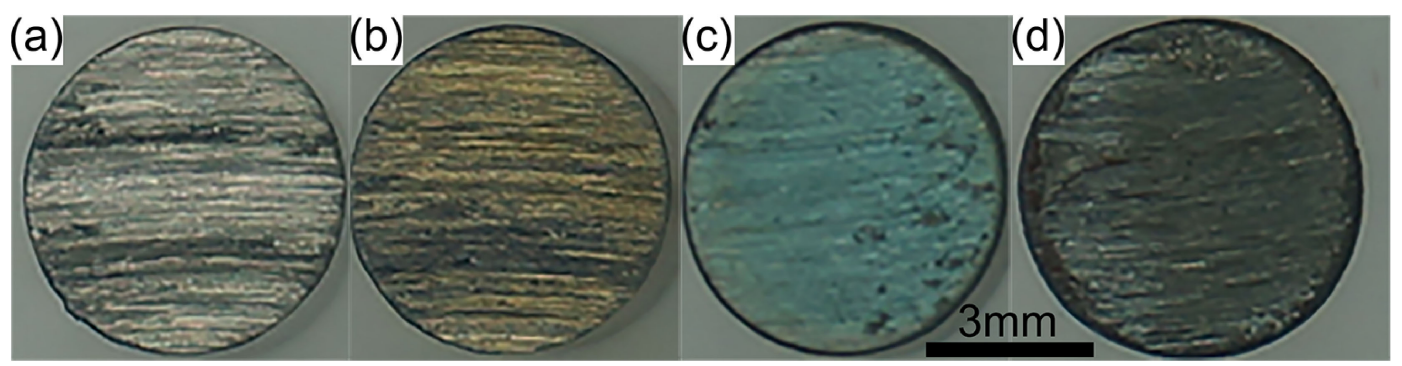

Fig. 5 Macromorphologies of worn surfaces of $38 \mathrm{CrNi} 3 \mathrm{MoV}$ steel at various temperatures: (a) $25^{\circ} \mathrm{C}$, (b) $200^{\circ} \mathrm{C}$, (c) $400^{\circ} \mathrm{C}$, (d) $600^{\circ} \mathrm{C}$.
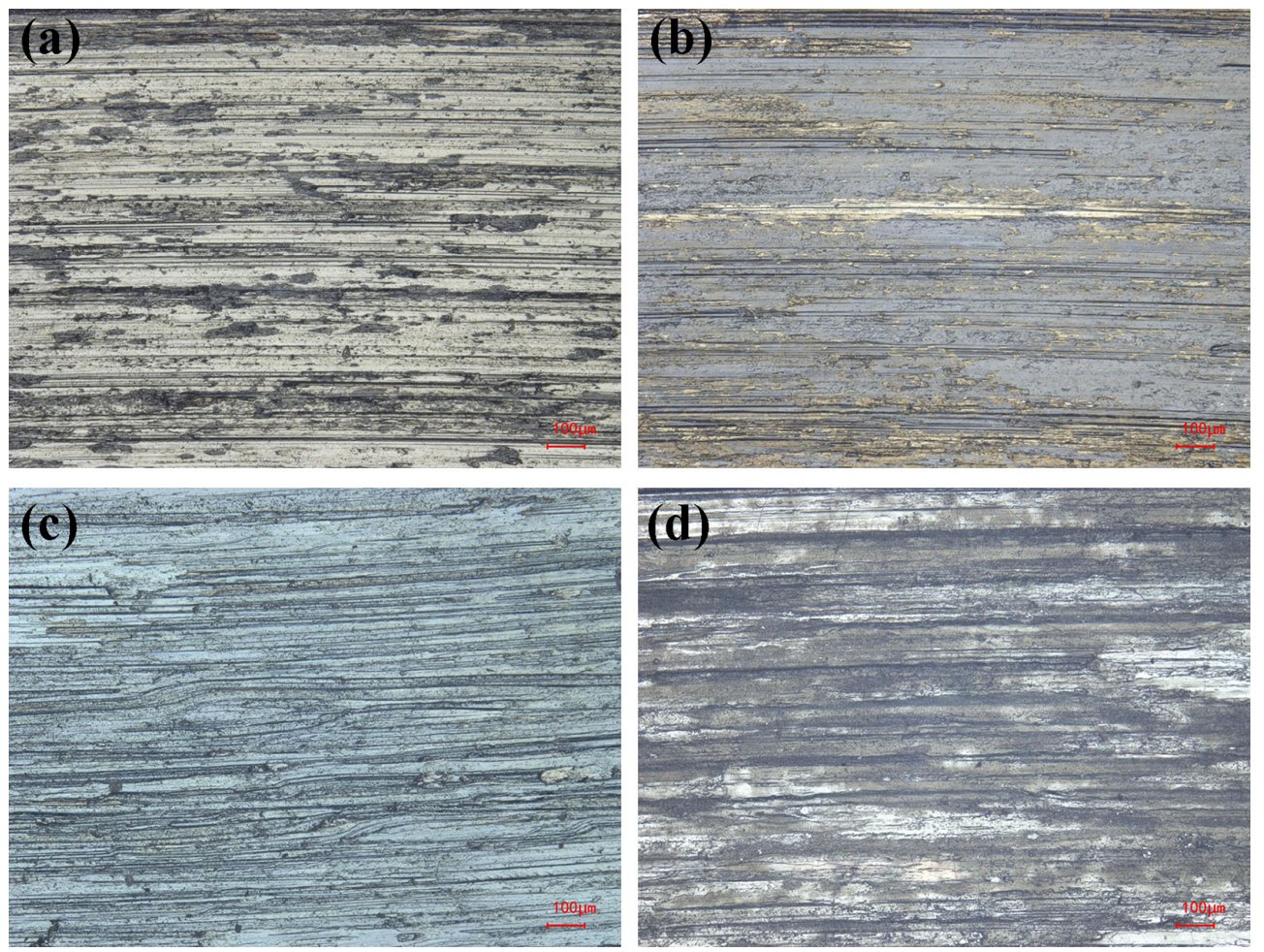

Fig. 6 Morphologies of worn surfaces of $38 \mathrm{CrNi} 3 \mathrm{MoV}$ steel at various temperatures: (a) $25^{\circ} \mathrm{C}$, (b) $200^{\circ} \mathrm{C}$, (c) $400^{\circ} \mathrm{C}$, (d) $600^{\circ} \mathrm{C}$.

worn surface and some furrows were present. At $400^{\circ} \mathrm{C}$, more furrows and signs of ripping appeared. When the temperature was $600^{\circ} \mathrm{C}$, the worn surface was covered with thick tribo-oxides.

Figure 7 illustrates the micro-morphologies of the worn surfaces of $38 \mathrm{CrNi} 3 \mathrm{MoV}$ steel at various temperatures. Rows of furrows and signs of smearing, yielding and ripping were found on the worn surface when the ambient temperature was $25^{\circ} \mathrm{C}$. A little black area also appeared, indicating that a small amount of oxide had formed. At an ambient temperature of $200^{\circ} \mathrm{C}$, the oxide layer covered the worn surface and little oxides spalled off from the worn surface. As the temperature reached $400^{\circ} \mathrm{C}$, a smooth, glazed oxide layer predominated the worn surface with a large number of wear particles and some rows of furrows. When the ambient temperature reached $600^{\circ} \mathrm{C}$, a thick oxide layer had formed on the worn surface, cracked and spalled.

The existence of the tribo-oxide layer could be identified more clearly by observing the worn sub-surface morphology. The cross-section morphologies of the worn surfaces of $38 \mathrm{CrNi} 3 \mathrm{MoV}$ steel at various temperatures are shown in Fig. 8 . At $25^{\circ} \mathrm{C}$, a thin oxide layer with a thickness of about
1-3 $\mu \mathrm{m}$ appeared in some areas of the worn surface of the $38 \mathrm{CrNi} 3 \mathrm{MoV}$ steel and the oxide layer was observed to have spalled off. When the ambient temperature was $200^{\circ} \mathrm{C}$, the worn surface was covered by a dense oxide layer with a thickness of $1-3 \mu \mathrm{m}$, which could effectively hinder the metal-metal contact between the disc and pin. When the ambient temperature was $400^{\circ} \mathrm{C}$, the oxide layer began to delaminate. A very thick oxide layer with a thickness of $20-30 \mu \mathrm{m}$ formed on the worn surface at $600^{\circ} \mathrm{C}$, completely covering the worn surface.

\section{Discussion}

Combined with the results of Fig. 5-8, the variation of the tribo-oxide layer on the worn surface and the wear behavior of $38 \mathrm{CrNi} 3 \mathrm{MoV}$ pin can be analyzed accurately. For the experimental tribo-system, as shown in Fig. 1, the friction coefficient increases significantly in the initial running-in period due to the adhesion between the two contact surfaces. Then Wear debris presented on the sliding surface and tribo-oxides the formed, the friction coefficient stabilize within a range of $0.3-0.4$ and did not change 

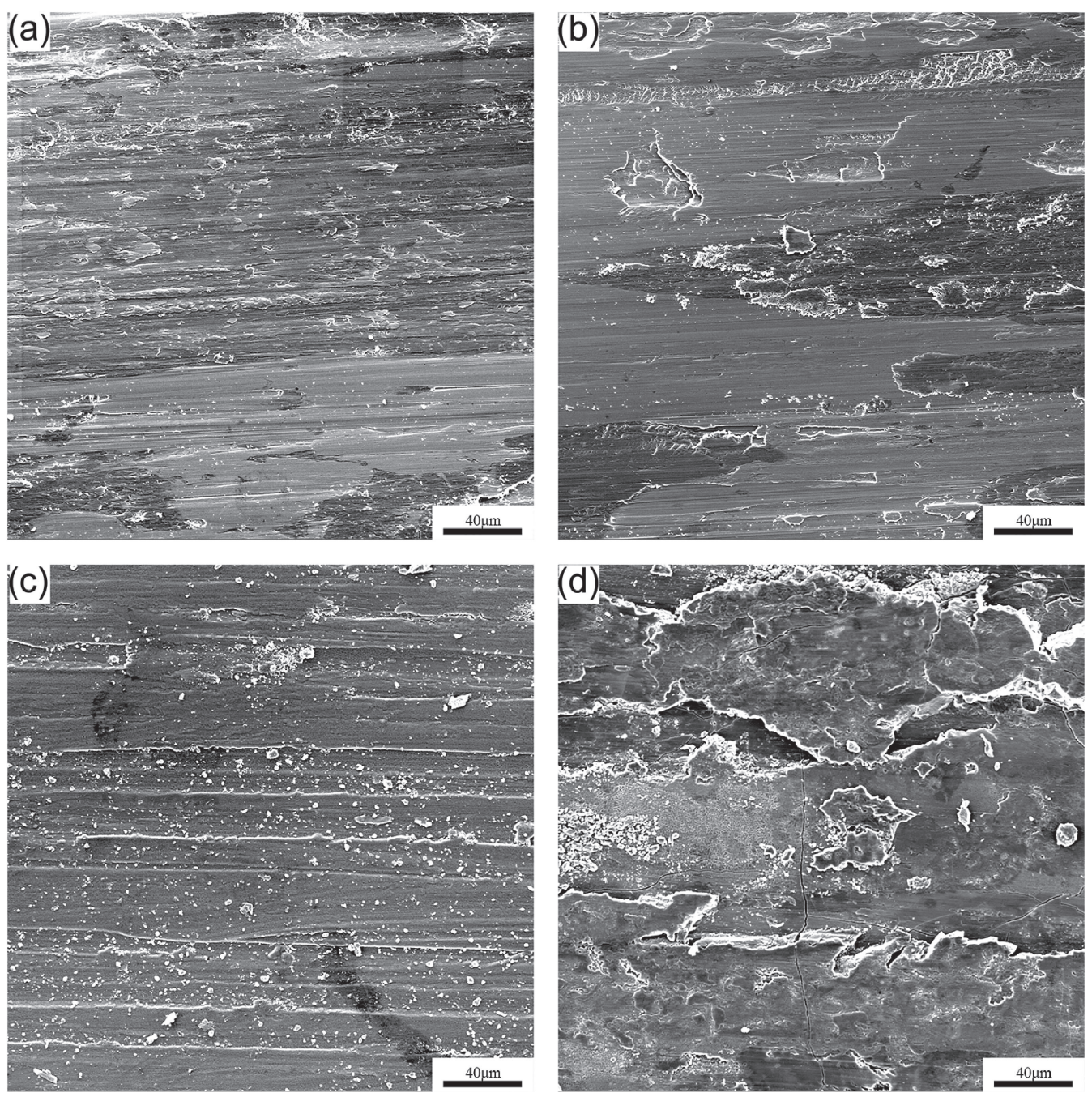

Fig. 7 Micromorphologies of worn surfaces of $38 \mathrm{CrNi3MoV}$ steel at various temperatures: (a) $25^{\circ} \mathrm{C}$, (b) $200^{\circ} \mathrm{C}$, (c) $400^{\circ} \mathrm{C}$, (d) $600^{\circ} \mathrm{C}$.
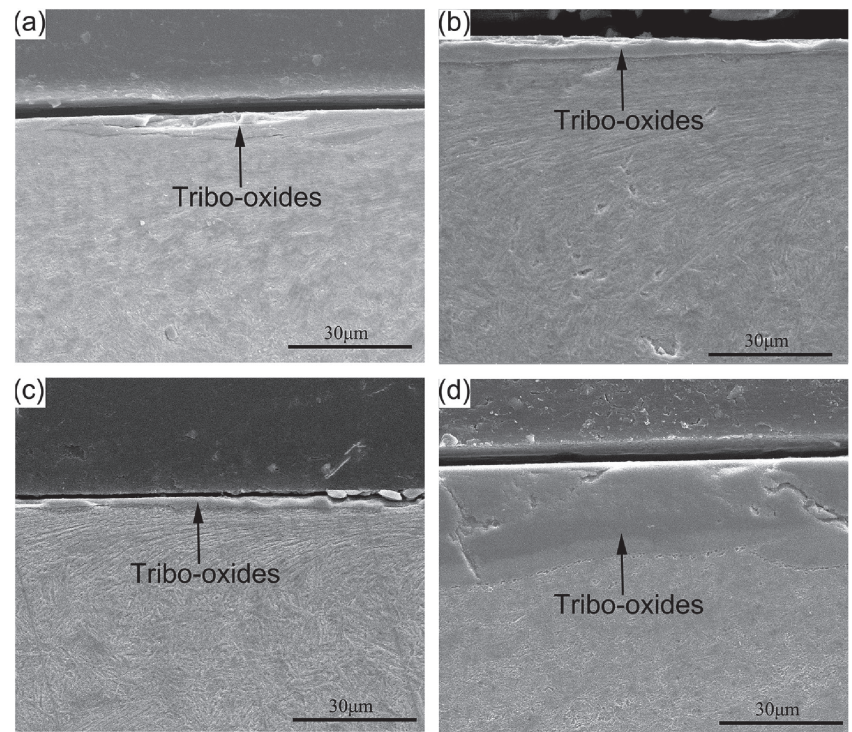

Fig. 8 Cross-section morphologies of worn surfaces of $38 \mathrm{CrNi3MoV}$ steel at various temperatures: (a) $25^{\circ} \mathrm{C}$, (b) $200^{\circ} \mathrm{C}$, (c) $400^{\circ} \mathrm{C}$, (d) $600^{\circ} \mathrm{C}$.

significantly with the test temperature. This can be explained on the basis of tribo-oxides. Due to the friction between the contact surfaces, oxidation of iron comes much easier. These tribo-oxides hindered the direct contact between metals. It is true that the tribo-oxides formed may be different in thickness and integrity, the "generation-migration-generation" process occurred at different ambient temperatures. The tribocomponents entered a stable process, the formation and migration of tribo-oxides and wear debris entered a state of dynamic balance.

Adhesive and abrasive wear prevailed in the M2$38 \mathrm{CrNi3MoV}$ steel tribo-system at ambient temperatures of $25^{\circ} \mathrm{C}$. The pin and the disc were in metal-metal contact with only a small amount of oxide on the worn surface (Fig. 5, 6, $7(\mathrm{a})$ ). These oxides spalled off in some areas and could not completely hinder the metal-metal contact. When the ambient temperature reached $200^{\circ} \mathrm{C}$, mild oxidation wear prevailed, and the oxide layer already covered the entire worn surface. Although the surface of the oxide layer showed partial adhesion (Fig. 6(b)) and furrows (Fig. 7(b)), the tribooxides hindered the metal-metal contact between the pin and disc and reduced the wear rate of the pin (Fig. 2). When the temperature was not higher than $400^{\circ} \mathrm{C}$, the $\left(H_{\text {disc }}-H_{\text {pin }}\right)$ was always around $400 \mathrm{HV}$ and the hardness of the disc remained much higher than the pin. Therefore, the variation in the performance of the disc could be ignored in this temperature range. Whether the tribo-oxides could remain on 
the worn surface depended on the hot hardness of the pin. At a temperature of 25 and $200^{\circ} \mathrm{C}$, the matrix could support the oxide layer because the hardness of the pin had changed very little.

Severe oxidation wear prevailed at a temperature of $400^{\circ} \mathrm{C}$. Though the $\left(H_{\text {disc }}-H_{\text {pin }}\right)$ value was stable at about $400 \mathrm{HV}$, the hardness of $38 \mathrm{CrNi} 3 \mathrm{MoV}$ matrix decreased at a temperature of $400^{\circ} \mathrm{C}$ which retained a weak strength to support the tribo-oxide layer and leading to the spalling of the oxide layer. The subsurface matrix softened and underwent increasing shearing as the temperature increased, resulting in the delamination of the oxide layer. ${ }^{19)}$ The "generation-migration-generation" process in the oxide layer continued to occur and led to an increase in the wear rate.

When the ambient temperature reached $600^{\circ} \mathrm{C}$, even though the hardness of the pin was greatly reduced, the wear rate of $38 \mathrm{CrNi} 3 \mathrm{MoV}$ steel decreased and the phenomenon of extrusive wear involved in Refs. 19), 30), 31) did not occur. The main reason for this was that the worn surface of $38 \mathrm{CrNi} 3 \mathrm{MoV}$ steel was covered with a large amount of oxides (Fig. 8(d)). Compared with $400^{\circ} \mathrm{C}$, the hardness of the pin experienced little change at $600^{\circ} \mathrm{C}$. The main change in the tribo-system was the drastic decrease in the disc's hardness. The hot hardness of the disc dropped below $600 \mathrm{HV}$ and the $\left(H_{\text {disc }}-H_{\text {pin }}\right)$ dropped below $300 \mathrm{HV}$ at this time, which caused the disc to be unable to effectively plow the oxide on the worn surface of $38 \mathrm{CrNi} 3 \mathrm{MoV}$. The thickness of the retained oxide layer not only prevented the metalmetal contact between the pin and disc but also coordinated the plastic deformation of the matrix. ${ }^{32)}$ As such, mild oxidation wear prevailed again at this temperature.

The wear rate data of $30 \mathrm{SiMn} 2 \mathrm{MoV}$ steel under the same experimental conditions reported in our previous work $^{33)}$ were also provided in Fig. 9 for discussion. Like $38 \mathrm{CrNi} 3 \mathrm{MoV}$ steel, the wear rate changed very little when the ambient temperature rose from $25^{\circ} \mathrm{C}$ to $200^{\circ} \mathrm{C}$, and increased at the temperature of $400^{\circ} \mathrm{C}$. Figure 10 shows both the hot hardness of the disc (M2 steel) and pin (38CrNi3MoV and $30 \mathrm{SiMn} 2 \mathrm{MoV}$ steel) and the difference between the hot hardness of the disc and pin $\left(H_{\text {disc }}-H_{\text {pin }}\right)$ at various temperatures. The variation of $\left(H_{\text {disc }}-H_{\text {pin }}\right)$ value at various temperatures for $\mathrm{M} 2-38 \mathrm{CrNi} 3 \mathrm{MoV}$ pairs was different from M2-30SiMn2MoV pairs as shown in Fig. 10(b). The $\left(H_{\text {disc }}-\right.$

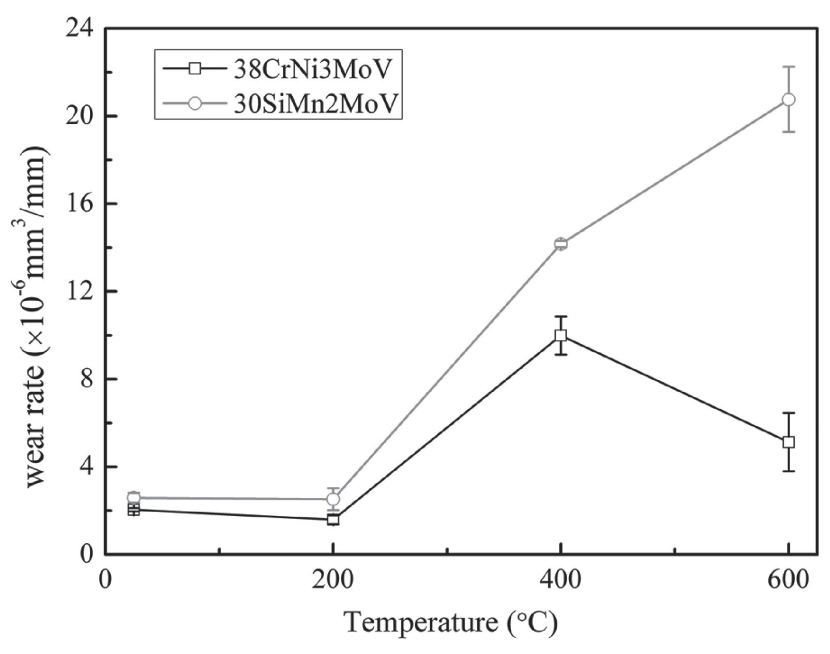

Fig. 9 Wear rates at various temperatures for $38 \mathrm{CrNi} 3 \mathrm{MoV}$ steel in this work and 30SiMn2MoV steel presented in Ref. 33).

$H_{\text {pin }}$ ) value of M2-30SiMn2MoV pairs increased at $400^{\circ} \mathrm{C}$ and stable at about $470 \mathrm{HV}$ when the temperature reaches $600^{\circ} \mathrm{C}$. For M2-30SiMn2MoV pairs, the $\left(H_{\text {disc }}-H_{\text {pin }}\right)$ value of increased at $400^{\circ} \mathrm{C}$ and stable at about $470 \mathrm{HV}$ when the temperature reaches $600^{\circ} \mathrm{C}$. The hot hardness of the disc dropped to about $100 \mathrm{HV}$, which indicated that the pin specimen is seriously softened and processes a low resistance to plastic deformation. The matrix softened did not retain the necessary strength to support the tribo-oxide layer. Plastic extrusion happened, the oxide film ruptured and peeled off with the matrix, leaving a small amount oxide film which cannot effectively prevented the metal-metal contact. As a result, the wear rate of $30 \mathrm{SiMn} 2 \mathrm{MoV}$ pin keep increasing when the test temperature increased to $600^{\circ} \mathrm{C}$.

The ambient temperature is a main factor determining the tribo-oxides as the hot hardness of the disc and pin changed with the test temperature. There is a correlation between the formation of tribo-oxides and the hardness of the pin/disc. The tribo-oxides exhibited different colors (as shown in Fig. 5) and phase compositions (as shown in Fig. 4) at various temperatures. However, the amount and final morphology of the oxide remaining on the worn surface depended on the $\left(H_{\text {disc }}-H_{\text {pin }}\right)$ and the hot hardness of the pin and disc. For the presented M2-38CrNi3MoV steel tribo-
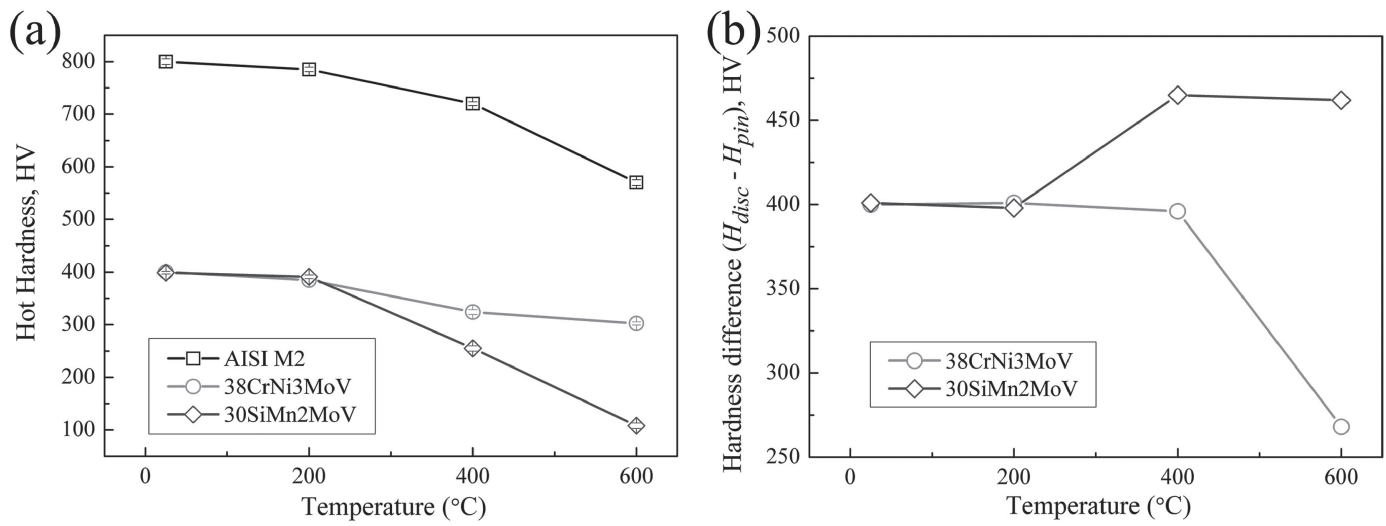

Fig. 10 The hot hardness of disc (M2 steel) and pin (38CrNi3MoV steel, 30SiMn2 MoV ${ }^{33)}$ ) at various temperatures: (a) hot hardness;

(b) the difference between the hot hardness of the disc and pin. 
system, when the $\left(H_{\text {disc }}-H_{\text {pin }}\right)$ was high (approximately $400 \mathrm{HV}$ at 25,200 and $400^{\circ} \mathrm{C}$ ), the disc could effectively plow the oxide layer produced on the worn surface of the pin and the oxide layer mainly depended on the pin's hardness. When the ambient temperature rose to $600^{\circ} \mathrm{C}$, the oxide layer became mainly depended on the hardness of the disc. The hardness difference between the disc and pin $\left(H_{\text {disc }}-H_{\text {pin }}\right)$ decreased to lower than $300 \mathrm{HV}$. The drastic decrease of the disc's hardness indicated that the disc became not effective in plowing the oxide layer formed on the worn surface of the pin. The retained oxide layer not only prevented the metalmetal contact between the pin and disc but also coordinated the plastic deformation of the matrix.

\section{Conclusion}

(1) $38 \mathrm{CrNi} 3 \mathrm{MoV}$ steel presented different wear rates at various temperatures due to the change in the amount and final morphology of the tribo-oxides on the worn surface.

(2) The main factor determining the formation of tribooxides on the worn surface of $38 \mathrm{CrNi} 3 \mathrm{MoV}$ steel was the ambient temperature. The amount and final morphology of the oxide remaining on the worn surface depended on the $\left(H_{\text {disc }}-H_{\text {pin }}\right)$ and the hot hardness of the pin and disc.

(3) For $38 \mathrm{CrNi} 3 \mathrm{MoV}$ steel, adhesive and abrasive wear prevailed at $25^{\circ} \mathrm{C}$ while mild oxidative wear prevailed at $200^{\circ} \mathrm{C}$. Severe oxidative wear was the dominant wear mechanism at $400^{\circ} \mathrm{C}$ and mild oxidative wear prevailed again at $600^{\circ} \mathrm{C}$.

\section{Acknowledgments}

The present work was financially supported by Beijing Key Laboratory for Corrosion-Erosion and Surface Technology, Beijing Municipal Education Commission Project (SYS100080419).

\section{REFERENCES}

1) I.A. Inman: Doctoral thesis, Northumbria University, Newcastle, (2004).
2) J. Joseph, N. Haghdadi, K. Shamlaye, P. Hodgson, M. Barnett and D. Fabijanic: Wear 428-429 (2019) 32-44.

3) Y. Zhang, K. Shimizu, K. Kusumoto, K. Tamura, H. Hara and J. Ito: J. JFS 88 (2016) 246-251.

4) X. Cheng, Z. Jiang, B. Kosasih, H. Wu, S. Luo and L. Jiang: Tribol. Lett. 63 (2016) 28.

5) F.H. Stott, D.S. Lin and G.C. Wood: Corros. Sci. 13 (1973) 449-469

6) H. Winkelmann, E. Badisch, M. Kirchgaßner and H. Danninger: Tribol. Lett. 34 (2009) 155-166.

7) M. Fink: Transactions of the American Society for Steel Treating 18 (1930) 1026-1034

8) J.F. Archard and W. Hirst: Proc. R. Soc. London, Ser. A 236 (1956) $397-410$.

9) T. Quinn, D.M. Rowson and J.L. Sullivan: Wear 65 (1980) 1-20.

10) J.L. Sullivan, T. Quinn and D.M. Rowson: Tribol. Int. 13 (1980) 153158.

11) J.E. Wilson, F.H. Stott and G.C. Wood: Proc. R. Soc. London, Ser. A 369 (1980) 557-574.

12) E. Marui, N. Hasegawa, H. Endo, K. Tanaka and T. Hattori: Wear 205 (1997) 186-199.

13) Y. Wang and T. Lei: Wear 194 (1996) 44-53.

14) A.F. Smith: Tribol. Int. 18 (1985) 35-43.

15) H. So, D.S. Yu and C.Y. Chuang: Wear 253 (2002) 1004-1015.

16) S.Q. Wang, M.X. Wei and Y.T. Zhao: Wear 269 (2010) 424-434.

17) Q.Y. Zhang, K.M. Chen, L. Wang, X.H. Cui and S.Q. Wang: Tribol. Int. 61 (2013) 214-223.

18) S.Q. Wang, L. Wang, Y.T. Zhao, Y. Sun and Z.R. Yang: Wear 306 (2013) 311-320.

19) M.X. Wei, S.Q. Wang, Y.T. Zhao, K.M. Chen and X.H. Cui: Metall. Mater. Trans. A 42 (2011) 1646-1656.

20) H.P. Hua, Y. Zhou, X.X. Li, Q. Zhang, X. Cui and S. Wang: Proc. Inst. Mech. Eng., Part J: J. Eng. Tribol. 229 (2015) 763-770.

21) D.A. Rigney: Annu. Rev. Mater. Sci. 18 (1988) 141-163.

22) D.A. Rigney: Tribol. Int. 30 (1997) 361-367.

23) B. Bhushan: Principles and Applications of Tribology, 2nd ed., (Columbus, Ohio, 2013).

24) M.X. Wei, S.Q. Wang, L. Wang, X.H. Cui and K.M. Chen: Tribol. Int. 44 (2011) 898-905.

25) S.Q. Wang, M. Wei, F. Wang, X.H. Cui and C. Dong: Tribol. Lett. 32 (2008) 67-72.

26) Y. Birol: Wear 269 (2010) 664-671.

27) D.A. Rigney: Wear 175 (1994) 63-69.

28) T. Akagak and D.A. Rigney: Wear 149 (1991) 353-374.

29) O.A. Zambrano, J.J. Coronado and S.A. Rodríguez: Surf. Coat. Tech. 282 (2015) 155-162.

30) O. Barrau, C. Boher, C. Vergne, F. Rezai-Aria and R. Gras: Karlstad Univ. 1 (2002) 81-94.

31) H. So, H.M. Chen and L.W. Chen: Wear 265 (2008) 1142-1148.

32) M.X. Wei, S.Q. Wang, X.H. Cui and K.M. Chen: Tribol. Trans. 53 (2010) 888-896.

33) D.A. Rigney and S. Karthikeyan: Tribol. Lett. 39 (2010) 3-7. 